\title{
The diabetic hand: a very neglected pathology. A Case Study \& Review of Literature
}

\author{
Alessandro Crisci ${ }^{1-3^{*}}$ \\ ${ }^{1}$ Unit of Dermosurgery Cutaneous Transplantations and Hard-to-Heal Wound "Villa Fiorita" Private Hospital, Aversa CE, Italy \\ ${ }^{2}$ Institute for the Studies and Care of Diabetcs, Abetaia, Casagiove CE, Italy \\ ${ }^{3}$ School of Medicine, University of Salerno Italy, 84084 Fisciano SA, Italy
}

"Corresponding author: Alessandro Crisci, Unit of Dermosurgery Cutaneous Transplantations and Hard-to-Heal Wound "Villa Fiorita" Private Hospital , 81031 Aversa (CE), Italy. Tel: +390823714196; Email: alessandrocrisci@libero.it

Citation: Crisci A (2018) The diabetic hand: a very neglected pathology. A Case Study \& Review of Literature,J Surg: JSUR-1134. DOI: $10.29011 / 2575-9760.001134$

Received Date: 11 May, 2018; Accepted Date: 31 May, 2018; Published Date: 06 June, 2018

\begin{abstract}
The term "diabetic hand" was born to describe the complications of the diabetes mellitus on the hand resulting in a rigid hand with a poor mobility. The traumatic wounds with soft tissue involvement increase the risk of infection. Staphylococcus aureus Methicillin-Resistant (MRSA) is the most common bacterium isolated in the hand infections. The case report of a type 2 diabetic patient, dialysed with chronic obstructive peripheral artery disease and Monckeberg sclerosis of the vessels of the hands, ischemic necrosis of the right-hand fingers is reported by the authors. In the diabetic patient the hands can be infected in the same way that feet could be infected too. Several amputation interventions have been performed with the intent of saving part of the hand.

The Diabetic Hand Syndrome (DHS) is an important pathology that requires strong antibiotics and surgery to avoid severe disability as rigidity, contracture and amputation. Apparently, in the last years good results are reported using antibiotic, surgical and hyperbaric treatment. In conclusion it would be wrong to ignore or underestimate this disease and any doctor should practice a scrupulous visit of the hands in the diabetic patient.
\end{abstract}

Keywords: Diabetic Hand; Gangrena of Meneley; Ischemia; Monckeberg's Sclerosis; Sepsis

\section{Introduction}

The Diabetic Hand Syndrome (DHS) is definite as a clinical condition based on a vascular, neuropathic and infective pathogenesis caused by a chronic hyperglicemy with or without a pre-existing ischemy triggered by traumatic lesions of the upper limbs. Our impression is that in the last 20 years the interest about this pathology is going decreasing so that most of the doctors ignore the existence of this disease [1]. The term "diabetic hand" was born to describe the complications of the diabetes mellitus on the hand resulting in a rigid hand with a poor mobility. The immunodeficiency causes a higher risk of severe hand infections, sometimes life-threatening. The outcome of the hand infection depends by the early diagnosis and treatment [2]. The morbility of the DHS in terms of loss job, inability and permanent disability compared to the diabetic foot is sharply higher. However, in the last years the decreasing interest is proved by the poor scientific publications on the DHS [3]. The compact anatomy of the hand promotes a rapid propagation of the infection with severe damages. The etiology of the disease is multi-factorial. The traumatic wounds with soft tissue involvement increase the risk of infection. The most common bacterium is the staphylococcus (Table 1) but also other microorganisms can be involved both as single bacterium infection and as polimicrobic infection including Grambacteria (Enterobacter, Streptococcus, Pseudomonas aeruginosa, anaerobic bacteria and fungal infection) $[4,5]$. 


\begin{tabular}{|c|c|c|}
\hline (a) Gram-positive organisms & $\begin{array}{c}\text { Number of } \\
\text { occurences }\end{array}$ & $\%$ \\
\hline Staphylococcus aureus & 24 & 34 \\
\hline Enterococcus spp & 6 & 8 \\
\hline Streptococcus spp & 4 & 5.6 \\
\hline Clostridium clostridiforme & 1 & 1.4 \\
\hline Total & $\mathbf{3 5}$ & $\mathbf{4 9}$ \\
\hline
\end{tabular}

\begin{tabular}{|c|c|c|}
\hline (b) Gram-negative organisms & $\begin{array}{l}\text { Number of } \\
\text { occurences }\end{array}$ & $\%$ \\
\hline Klebsiella pneumoniae & 5 & 7 \\
\hline Citrobacter freundii & 5 & 7 \\
\hline Marganella morganii & 4 & 5.6 \\
\hline Enterobacter spp & 4 & 5.6 \\
\hline Pasteurella multocida & 3 & 4.2 \\
\hline Escherichia spp & 3 & 4.2 \\
\hline Proteus vulgaris & 3 & 4.2 \\
\hline Pseudomonas aeruginosa & 2 & 2.8 \\
\hline Aeromonas caviae & 1 & 1.4 \\
\hline Eubacterium lenticus & 1 & 1.4 \\
\hline Acinetobacter spp & 1 & 1.4 \\
\hline Edwardsiella tarda & 1 & 1.4 \\
\hline Xanthomonas multophilia & 1 & 1.4 \\
\hline Total & 34 & 47.6 \\
\hline
\end{tabular}

Table 1: (a) Gram-positive organisms in 57 specimens; and (b) gramnegative organisms in 57 specimens (from Lamm e Choi modified) [4].

Staphylococcus aureus Methicillin-Resistant (MRSA) is the most common bacterium isolated in the hand infections. The fungal infection can result in a trivial onychomycosis but also in a life-threatening disease if the infection is severe with deep layers involvement. The viral infections are rare, anyway sometimes Papillomaviridae, Herpesviridae, Picornaviridae (coxsackievirus and enterovirus) and Poxviridae (orthopoxvirus and parapoxvirus) were isolated in patients with DHS. In the study published by Lamm and Choi (2004) the $49 \%$ of the infections were caused by Gram+ bacteria and the $47,6 \%$ by Gram- bacteria. Staphylococcus aureus was the most common bacterium isolated in the hand infections (34\%). Enterococcus was isolated in the $8 \%$ of the cases. The Gram- bacteria Klebsiella pneumoniae, Citrobacter spp, Morganella morganii and Enterobacter spp were isolated respectively in $7 \%, 7 \%, 5,6 \%$ and $5,6 \%$ (Table 1) [4]

The DHS is more common in patients affected by diabetes mellitus type II rather than diabetes mellitus type I. Anyway, the early diagnosis and treatment are more important than the type of diabetes and not all of the symptoms are related to the diabetes. The natural evolution of the DHS is the fulminant sepsis due to the infection and to the progressive hand necrosis (Meleney's gangrene).

\section{Review of the Literature}

Usually the hand is in an advanced condition of palmar deep sepsis and/or soft tissue infection. Often a partial amputation must be performed and nevertheless the mortality rate is significant. The stereotypical sepsis characteristics in the diabetic hand of the tropical population were studied by Gill, et al. (2003) [6] and they suggested the term of "tropical diabetic hand syndrome". We have poor data on this syndrome that suggest poor results. The outcome data on the "tropical diabetic hand syndrome" are limited, but the information available generally suggests poor results. The study of Akintewe, et al. in 1984 [1] indicates that in 4 patients out of 5 a partial amputation was necessary. In the most representative study (31 patients in Tanzania), Abbas, et al. [6] shows that in the 13\% of the cases a full arm amputation was performed with a significant mortality rate $(13 \%)$. These patients would need a prolonged hospitalization with infusional antibiotics and 2/3 would need a surgical treatment (debridment, incision and drain or amputation).

Bacteria are the most involved microorganisms, but also fungal, viral and protozoal infections are described [3, 7]. In the diabetic hand infections Gram- bacteria were isolated in the $52 \%$ of patients. In the DHS Gram- infections were reported in $52 \%$ [8]. Gram- predominancy (Pseudomonas 10,6\%, Proteus 7,8\%, Enterobacter 5,7\%), Gram+ bacteria (S. aureus 15,6\%, Streptococcus beta-haemolyticus $12,1 \%$, S. viridans $7,1 \%$ ) were found in diabetic patients. Candida albicans was found just in the diabetic hand group $(2,8 \%)$ (Table 2$)$.

\begin{tabular}{|c|c|c|c|c|}
\hline Organism & \multicolumn{2}{|c|}{ Diabetic hand } & \multicolumn{2}{c|}{ Non-diabetic hand } \\
\hline & $\mathrm{N}$ & $\%$ & $\mathrm{~N}$ & $\%$ \\
\hline S. aureus & 44 & $15.60 \%$ & 58 & $37.70 \%$ \\
\hline S.epideridis & & & 24 & $15.60 \%$ \\
\hline Strept. $\beta$-Haem.. & 34 & $12.10 \%$ & 8 & $5.20 \%$ \\
\hline S. viridans & 20 & $7.10 \%$ & & \\
\hline Enterococcus & & & 18 & $11.70 \%$ \\
\hline Pseudomonass & 30 & $10.60 \%$ & 8 & $5.20 \%$ \\
\hline E.coli & 94 & $33.30 \%$ & 18 & $11.70 \%$ \\
\hline K. pneumoniae & & & 6 & $3.90 \%$ \\
\hline
\end{tabular}




\begin{tabular}{|c|c|c|c|c|}
\hline Klebsiella $\mathrm{sp}$ & & & 4 & $2.60 \%$ \\
\hline Proteus & 22 & $7.80 \%$ & & \\
\hline Enterobacter & 16 & $5.70 \%$ & 4 & $2.60 \%$ \\
\hline Aerobes & 14 & $5 \%$ & 6 & $5.20 \%$ \\
\hline Candida & 8 & $2.80 \%$ & & \\
\hline
\end{tabular}

Table 2: Frequency of organisms isolated on culture.

The rate of Gram- bacteria was between $31-73 \%$ in workers [2]. Different groups of Gram- bacteria were reported in patients affected by diabetes. These groups include: E. coli $0,72-$ 4,2\% [2], Proteus (Vulgaris Proteus in 4,2\%) [2], Pseudomonas aeruginosa (1,3-7,2\%) [2], Klebsiella (3,5-7\%) [2], Enterobacter (1,9-5,6\%) [2] and Aerobacter aerogens in 0,72\% [2]. Klebsiella was the most common Gram- bacterium isolated jointly with Staphylococcus in polimicrobic infections (Jalil, et al.) [9] and Klebsiella, Enterobacter, Proteus and E. coli, were found in $25 \%$ of microorganisms by Belcher, et al. [10]. Connor, et al. [11] reported Gram- bacteria in 31\% including Escherichia coli, Pseudomonas aeruginosa, Proteus vulgaris, Klebsiella, Serratia, Haemophilus, Enterobacter, Eichenella, Pasteurella and Neisseria. Dorko, et al. [12] reported Neisseria spp., Staphylococcus Coagulase negative between 5,7\% and 12,6\% (8); Streptococcus spp in 5,6-16\% [2]. Staphylococcus $\beta$-haemolyticus were mostly $S$. pyogenes between 3,6 and 12,5\% [2]. Dorko et al. [12] reported Streptococcus $\beta$-haemolyticus in $22,4 \%$. Not- $\beta$-haemolyticus S.Viridians were found in 1,3\% [7], 2,16\% [7]. Stevenson, et al. [13] reported $S$. faecalis in 0,7\%-1,7\%. Streptococcus agalactiae was isolated in a patient with diabetic hand [2]. Enterococcus was isolated in four cases and in three of them it was E. faecalis (9\%) [2], while
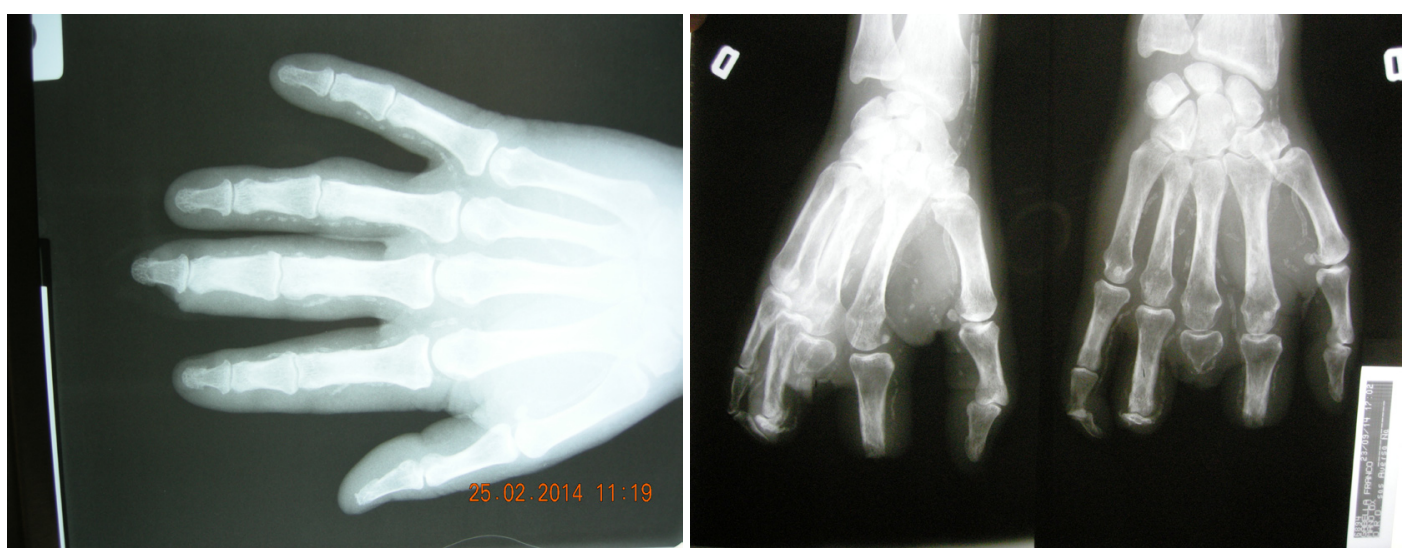

Figure 1: (A) X-ray left hand (B) right hand.

Then we decide to perform a tissue debridement. The surgical treatment is very gentle as the small vessels disease is really nasty and irreversible, intractable, which conditions a perfusion however reduced, so it's primary to avoid high pressure tissue zone (tight stitches, folded flaps...) that could be the trigger for the ischemic necrosis. The use of dermal replacement based on ialuronic acid $\left(\mathrm{HMPA}^{\circledR}\right)$ (Figure 2). Allows a reconstructive surgery with functional preservation of the hand (07.01.2015). 

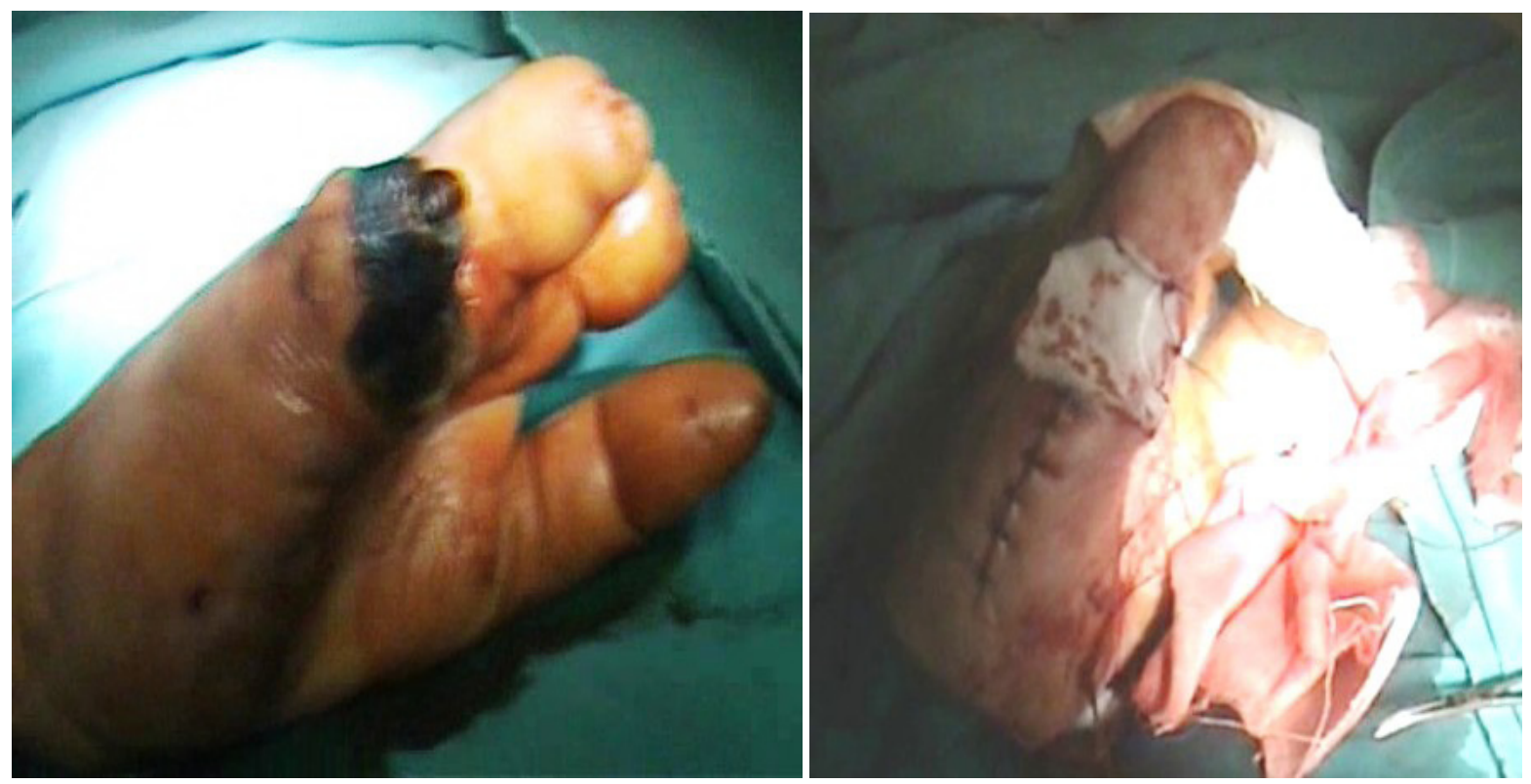

Figure 2: Partial resection V finger with dermal graft bioconductive $\left(\mathrm{HMPA}^{\circledR}\right)$ (07.01.2015).

At the right hand, furthermore we perform a partial resection of the IV finger (01.03.2017) (Figure 3,4) shows at MRI the vascular and bone situation with evidence of vessels calcification (Monckeberg's sclerosis).

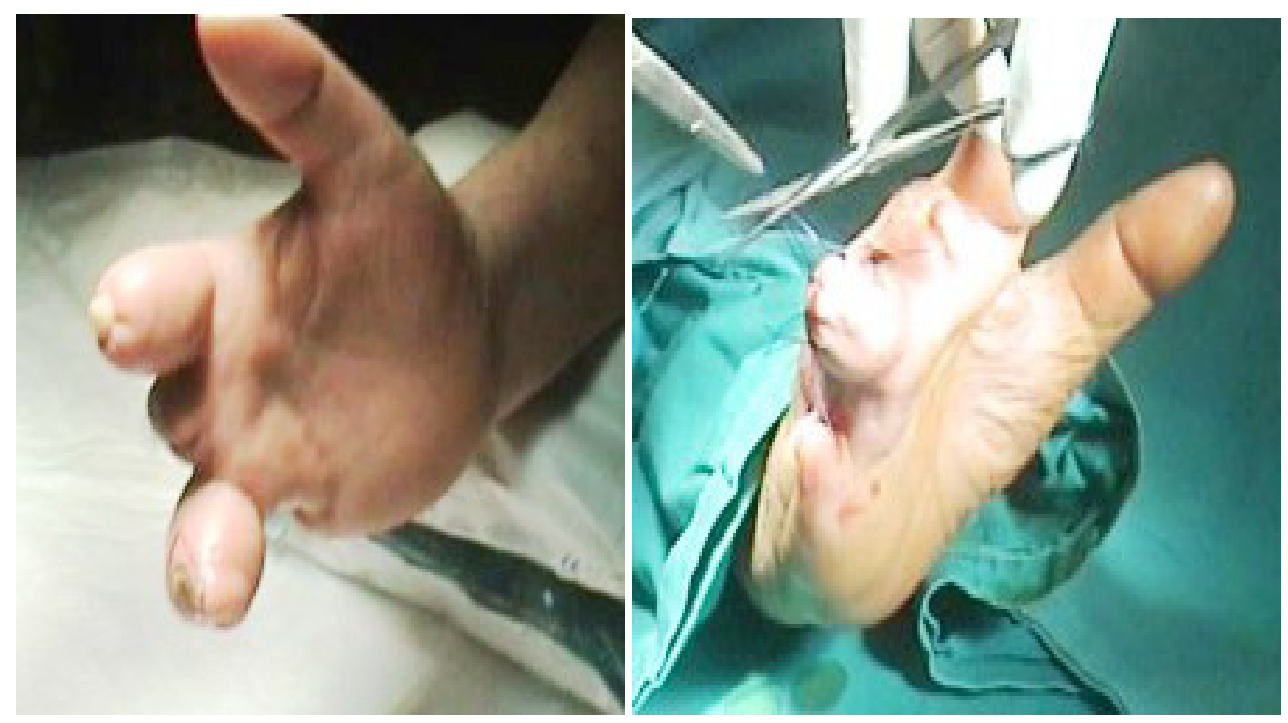

Figure 3: Partial resection IV finger (01.03.2017). 


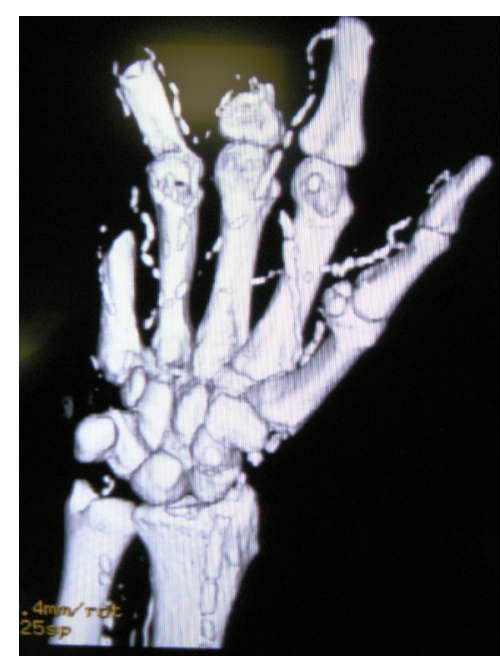

Figure 4: Hand MRI with vessels calcification.

One month after begins ischemic necrosis of the I finger (Figure 5) so a metacarpophalangeal joint resection is performed (5.4.2017) (Figure 6) with diaphyseal resection of the I metacarpus and closing using a sliding flap. Two months after we perform a surgical revision of the II finger (Figure 7) and a partial resection of the proximal phalanges (21.6.2017). The current situation is shown in (Figure 8).

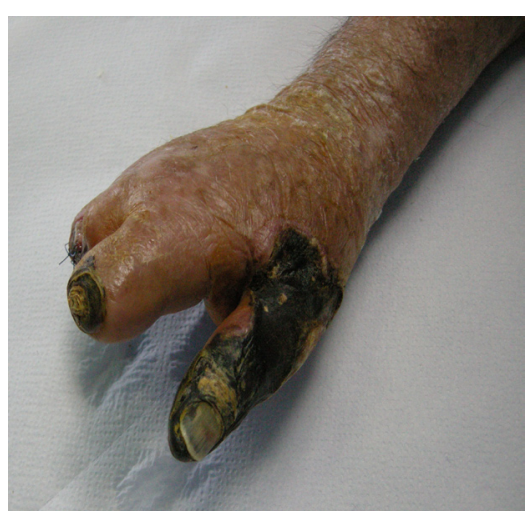

Figure 5: Ischemic necrosis I finger (Monckeberg's sclerosis).
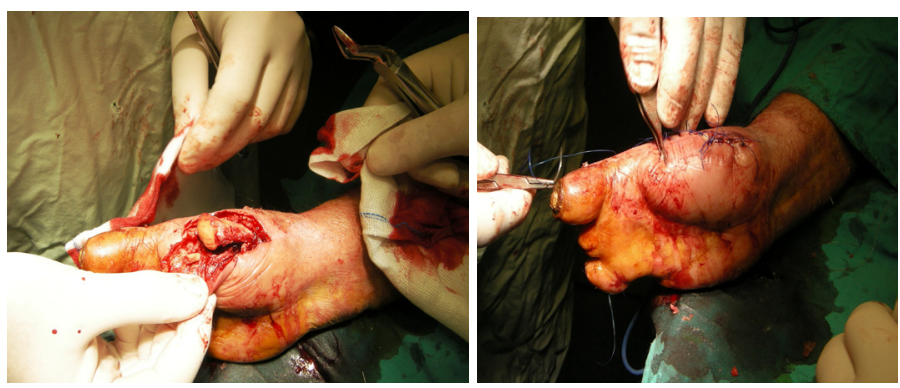

Figure 6: I finger metacarpophalangeal joint resection (5.4.2017).
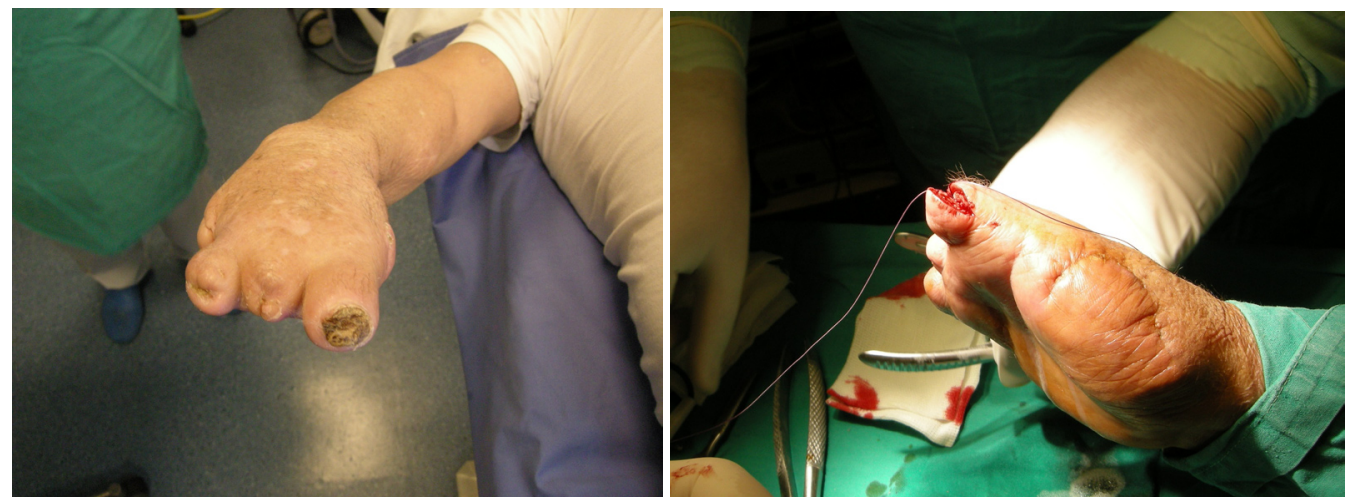

Figure 7: Partial proximal phalanges resection II finger (21.6.2017). 


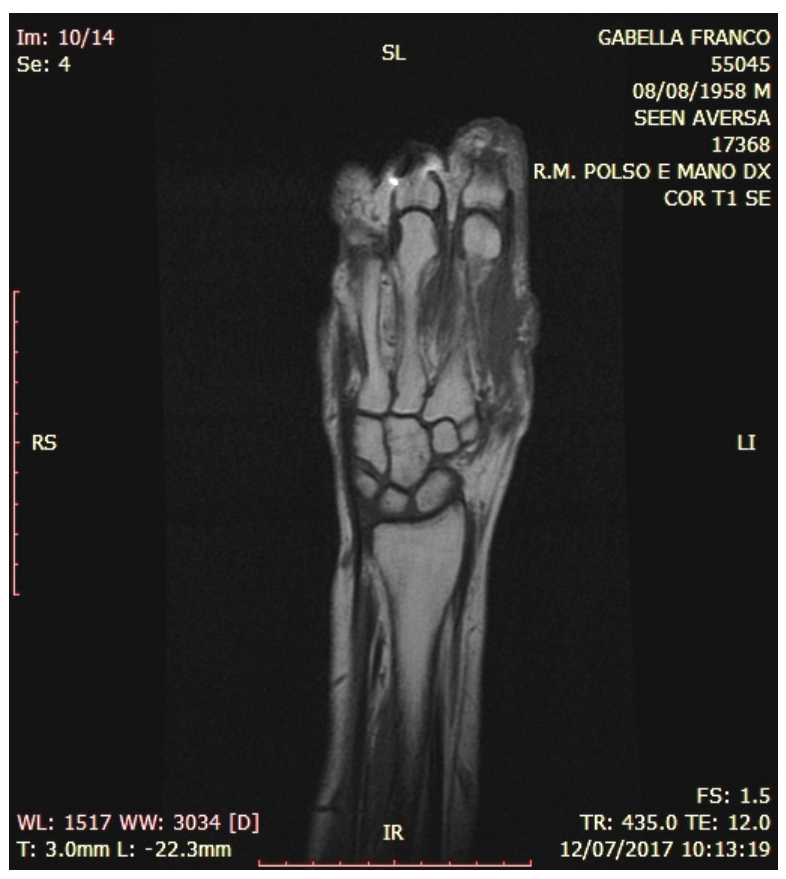

Figure 8: Current situation MRI 05/10/2017.

\section{Discussion}

Not everybody knows that in the diabetic patient the hands can be infected in the same way that feet could be infected too. (Montes de Oca 2008) [14].

Three are the causes of the ischemia in the dialysis patient's hand:

1. Arteriovenous fistula that steals oxygenated blood to the hand;

2. Big vessels disease that prevents blood from perfusing the hand;

3. Small vessels disease (metacarpal and digital vessels) acts as another obstacle to the hand's blood circulation.

The associated factors in the diabetic hand syndrome are similar to the associated factors in the lower limbs syndrome: 1 . High levels of glycemia. 2. Neuropathy due to the hyperglycemia, metabolic pathway that leads to an increased intraneural sorbitol level. The not-zymotic proteic glycation determines a depletion of the myoinositol levels and ATP decreased levels and neuronal degeneration, slower conduction velocity and higher glycated haemoglobin, proving medium-high levels of glycemia in the last six-eight weeks. 3. The vascular theory: hyperglycemy causes reologic modifies with a subsequent increased endoneural vascular resistance, blood flow reduction and neural hypoxemia. 4. The diabetes mellitus is a risk factor for the arteriolar compromising and the atheroma making process, progression and complications (stenosis, obliteration) with a decreased blood flow, perfusion pressure and ischemia. 5. Mechanical, chemical, physical, thermal or biological trauma are risk factors.

In our review, gram+ bacteria were isolated in the $50 \%$ of the hand infections and the most common bacterium was $\mathrm{S}$. aureus (Tab. II). According to this result we use flucloxacillin and erythromycin in the first line treatment regardless to the fact that in the DHS Gram- bacteria were found too. Diabetes promotes infections and has negative aftermath on the carbohydrate metabolism and glycemia. Firstly, Mann and Peacock [15] noted a Gram- predominancy in DHS in 1977, subsequently Francel, et al. [16] had different results with a mixed colture grow (63\%). These infections are related with a more severe tissue damage and secondary deformity. In 1998, in a 12 years study, Gunther [17] enlisted 128 diabetic patients. Mansigh and Sawh [18] used a double antibiotic therapy to destroy both Gram+ and Grambacteria. This predominancy inversion was not demonstrated in others high risk group as in the alcohol addiction and abuse, HIV patients, intravenous drugs addicts and steroids addiction. Kour, et al. [19] reported the negative effects of the gram- and mixed infections on the wounds. In the Lamm and Choi study, 3 out of 5 diabetic patients had a Gram- infection and required surgery and 2 or more fingertip amputations. It demonstrates the importance to choose the right antibiotics to treat Gram+ and Gram- infections. Gentamicin and penicillin penicillinase resistant (cloxacillin, ampicillin, penicillin G) combination could be the best first line treatment but the renal function and gentamicin blood levels must be monitorated.

\section{Conclusion}

The diabetic hand syndrome is common in young-adult people, in diabetes mellitus type II with a poor metabolic control and subsequent high level of the glycated haemoglobin, therefore with a high risk of complications (neuropathy of peripheral arteries). Trauma is the trigger for the infection process, late diagnosis and treatment lead to a high amputation risk and to an increased morbidity and mortality. The surgical treatment should: save life, preserve the function and, lastly, look out for aesthetics. Based on evidences, we can divide the DHS in 4 phases: 1 . superficial wound and ulcer, deep wound and ulcer, 3. Abscess and osteomyelitis, 4. Necrosis and gangrene. The DHS is an important pathology that requires strong antibiotics and surgery to avoid severe disability as rigidity, contracture and amputation. The success depends by an early diagnosis and antibiotic tratment in the first 24-48h with immobilization of the limb. If the infection is not under control the surgical option must be considered (incision, drain, debridment or amputation). The right choice of the antibiotics depends by the knowledge of the most common involved microorganisms. Once we know the microorganisms involved we should change the 
antibiotics based on the antimicrobial susceptibility.

In the last 10 years the relation among risk factors, mostly diabetes mellitus and Gram- infections, has been studied. The Gram- infections can't be treated just with a first line antibiotic treatment but these patients should be treated in hospital to treat the hand infection and to optimize the metabolic control of the disease, also using insulin. Though the bacteria involved in skin and tissue infections are very common (Gram+, Staphylococcus, Streptococcus), sometimes bowel bacteria are involved (Gramand an Aerobes). The first line treatment provides the use of broadspectrum intravenous antibiotics and possibly the surgical drain in case of abscess. The late treatment increases the risk of amputation. In case of amputation or loss of function after surgery rehabilitation should be considered. Apparently, in the last years good results are reported using antibiotic, surgical and hyperbaric treatment. In conclusion it would be wrong to ignore or underestimate this disease and any doctor should practice a scrupulous visit of the hands in the diabetic patient.

\section{References}

1. Akintewe TA, Odusan O, Akanji O (1984) The diabetic hand - 5 illustrative case reports. Br J Clin Pract 38: 368-371.

2. Yacoubi A, Al-Shobaili H (2014) Clinical and microbiological characteristics of hand infection in female patients with diabetes attending University in qassim, Saudi Arabia. Ibnosina J Med B S 2014: 85-90.

3. Canaves Y, Paròn L (2013) Sìndrome de mano diabética. Rev Méd. Rosario 79: 118-125.

4. Lamm MMY, Choi AKY (2004) Pyogenic hand infection-Importance of Gram-negative Organisms. Hong Kong J Orthop Surg 8: 28-32.

5. Proubasta Renart I (2015) La mano diabética. Rev Iberoam Cir Mano 43: 135-141.

6. Gill G, Archibald L, Abbas ZA (2003) Diabetic hand infections in the tropics, Diabetes' Voice 48: 17-19.
7. Mozzarella R, Dubbioso R, Manganelli F, Perretti A, Saldalamacchia G (2014) Un caso di ulcere alle dita delle mani in una paziente affetta da diabete mellito di tipo 1. G It Diabetol Metab 34: 82-84.

8. Schiavon F, Circhetta C, Dani L (2004) La mano diabetica. Reumatismo 56: 139-142.

9. Jalil A, Barlaan PI, Fung BK, Ip JW (2011) Hand infection in diabetic patients. Hand Surg 16: 307-312.

10. Belcher HJCR, Clare TD (2003) Hand Infections. Current Orthopaedics 17: 28-43.

11. Connor RW, Kimbrough RC, Dabezies EJ (2011) Hand infections in patients with diabetes mellitus. Orthopedics 24: 1057-1060.

12. Dorko E, Jautovà J, Pilipcinec E, Tkàcikovà L (2004) Occurrence of Candida strains in cases of paronychia. Folia Microbiol (Praha) 49: 591-595.

13. Stevenson J, Anderson IVR (1993) Hand infections: An audit of 160 infections treated by an accident and emergency department. J Hand Surg $\mathrm{Br}$ 18: 115-118.

14. Montes de Oca NJ, Córdoba GH, Mondragón CMA, Jaramillo GA, López OE, et al. (2008) Sindrome mano del diabético. Reporte de casos, Toluca, Estrado de México. Rev Mex Angiol 36: 14-20.

15. Mann RJ and Peacock JM (1977) Hand infections in patients with diabetes mellitus. J Trauma 17: 376-380.

16. Francel TJ, Marshall KA, Savage RC (1990) Hand infections in the diabetic and diabetic renal transplant recipient. Ann Plast Surg 24: 304-309.

17. Gunther SF, Gunther SB (1998) Diabetic hand infections. Hand Clin 14: 647-656.

18. Mansingh A, Sawh DM (2001) Hand infections in Jamaica. West Indian Med J 50: 309-312.

19. Kour AK, Looi KP, Phone MH, Pho RWH (1996) Hand infections in patients with diabetes. Clin Orthop 331: 238-244. 